\title{
ANALISA PENENTUAN PERUBAHAN CALON PENERIMA RASTRA (BERAS SEJAHTERA) DENGAN METODE SIMPLE ADDITIVE METHOD (SAW) DI DESA HUIDU KABUPATEN GORONTALO
}

\author{
Tri Pratiwi Handayani \\ Sistem Informasi, Fakultas Sains dan Teknologi, Universitas Muhammadiyah Gorontalo \\ Jl. Prof. Dr.Mansoer Pateda, Pentadio Timur, Kabupaten Gorontalo \\ tripratiwi@gmail.com
}

\begin{abstract}
Abstrak - Tujuan penelitian ini adalah menerapkan algoritma Simple Additive Method (SAW) dalam kasus penentuan perubahan calon penerima Rastra (Beras Sejahtera) di Desa Huidu Kabupaten Gorontalo. Algorima SAW (Penambahan bobot sederhana) adalah salah satu algoritma sistem pendukung keputusan yang mampu mendukung proses pengambilan keputusan yang dikategorikan sebagai multi kriteria decision making (MADM) atau pengambilan keputusan yang melibatkan banyak kriteria. Metode ini terdiri dari beberapa tahap. Pertama Matriks alternatif dibuat terlebih dahulu. Matriks alternatif merupakan matriks yang berisi alternatif alternatif yang akan dirangking pada akhir proses. Dalam kasus ini alternatif adalah nama - nama calon penerima Rastra yang akan dievaluasi pada rapat musyawarah desa. Kedua Matriks kriteria dibuat untuk menjadi indikator prioritas dalam mendukung keputusan. Tahap ketiga adalah penentuan atribut biaya dan atribut keuntungan dari kriteria yang telah ditetapkan. Tujuannya adalah membedakan kriteria yang bersifat keuntungan dan kriteria yang bersifat biaya. Keempat adalah penentuan bobot dari kriteria yang telah ditetapkan. Pada kasus ini diambil bobot bernilai 4 sebagai bobot yanng tetinggi dan bobot bernilai 1 sebagai bobot yang terendah. Penentuan nilai bobot pada kasus ini berdasarkan hasil wawancara dengan aparat desa. Kelima, melakukan normalisasi bobot dengan menggunakan persamaan. Keenam, menentukan preferensi alternatif terbobot. Sehingga didapatkanlah matriks keputusan.Dari hasil penelitian menunjukkan algoritma ini mampu memberikan ranking kelayakan calon Rastra.
\end{abstract}

Keywords - SAW, SPK, Rastra.

\section{PENDAHULUAN}

Latar belakang penelitian ini adalah untuk mencari solusi alternatif bagi masalah penentuan revisi calon penerima Rastra (Beras Sejahtera) melalui algoritma sistem pendukung keputusan yaitu metode Simple Additive Method (SAW). Program subsidi pangan (beras) Rastra adalah untuk masyarakat berpendapatan rendah.Tujuan Program Rastra adalah mengurangi beban pengeluaran KPM (Keluarga Penerima Manfaat) melalui pemenuhan sebagian kebutuhan pangan beras [3]. Sasaran Program Rastra adalah berkurangnya beban pengeluaran KPM dalam mencukupi kebutuhan pangan beras melalui penyaluran beras bersubsidi dengan alokasi sebanyak $15 \mathrm{~kg} / \mathrm{KPM} /$ bulan atau sesuai dengan kebijakan Pemerintah Pusat. Keluarga yang berhak menerima beras dari Program Rastra yaitu keluarga yang terdapat dalam DPM-1 (Daftar Penerima Manfaat-1) Rastra. Melalui Musyawarah desa (Musdel) ditetapkan keluarga yang diganti/ dikeluarkan dari DPM dan keluarga pengganti/masuk ke dalam DPM sebagai calon penerima Rastra. KPM Rastra yang dapat diganti/dikeluarkan dari DPM adalah KPM yang pindah alamat ke luar desa/kelurahan/pemerintah setingkat, KPM yang seluruh anggota keluarganya sudah meninggal, dan KPM yang dinilai oleh Mudes/Muskel sudah tidak layak sebagai penerima Rastra Revisi DPM dilakukan melalui Rapat
Musyawarah Desa dan hasilnya kemudian diajukan ke Dinas Terkait. Dalam Musdel inilah sistem pendukung keputusan dapat di implementasikan, untuk memberikan pendukung keputusan dalam kelayakan penerima Rastra. Penelitian ini mengambil studi kasus di Desa Yosonegoro yang berada pada kecamatan Limboto Barat Kabupaten Gorontalo. Penelitian ini sangat penting karena memiliki manfaat yaitu membantu aparat desa untuk mempercepat dan menjaga keobjektivitasan hasil keputusan revisi calon penerima Rastra.

\section{KAJIAN LITERATUR}

[1] menggunakan algoritma Simple Additive Weighting (SAW) dalam seleksi penerima beras untuk keluarga miskin (Raskin) pada Desa Golantelpus. Perbedaan dengan penelitian ini adalah penelitian ini diterapkan pada Desa Huidu.

[2] menggunakan algoritma SAW dalam penentuan calon penerima Raskin pada studi kasus Kabupaten Nganjuk. Perbedaannya dengan penelitian yang diajukan adalah desa tempat studi kasus dan kriteria yang menjadi pertimbangan keputusan. Pada [2] kriteria yang digunakan adalah luas lantai rumah per meter persegi, jenis lantai rumah, jenis dinding rumah, penghasilan kepala keluarga perbulan, pekerjaan kepala keluarga dan status kepemilikan. Sedangkan pada penellitian ini kriteria yang digunakan sebagai pertimbangan adalah sesuai dengan panduan Rastra yaitu, jumlah 
anggota keluarga, jumlah anggota keluarga bayi dan balita, kepala keluarga wanita dan lain - lain.

[3] menerapkan sistem pendukung keputusan di Desa Puupi Kecamatan Kolono kabupaten Konawe Selatan. Adapaun perbedaan dengan penelitian diajukan adalah pada kriteria yang digunakan. Pada penelitian [3] kriteria pendukung adalah keterangan tempat tinggal yang terdiri dari status rumah, luas rumah, lantai rumah dan lain-lain, harta yang terdiri dari pekerjaan, jumlah penghasilan dan jumlah pengeluaran dan jumlah aset. Kriteria lain adalah kesehatan seperti sarana obat dan sumber biaya.

[4] menerapkan saw untuk pengambilan keputusan raskin dengan melibatkan kriteria aspek pangan seperti rata-rata frekuensi makan dalam sehari, aspek tempat tinggal seperti status rumah yang ditempati, luas rumah yang dihuni dan jenis lantai rumah, model rumah yang dihuni, aspek ketersediaan listrik. Kriteria ini cukup lengkap, namun belum sesuai dengan buku panduan Rastra tahun 2017 yang hanya menitikberatkan pada kriteria jumlah tanggungan, jumlah balita, kepala keluarga perempuan dan lain - lain.

\section{METODOLOGI PENELITIAN}

Simple Additive Weighting Method (SAW) sering juga dikenal dengan metode penjumlahan terbobot. Konsep dasar metode SAW, adalah mencari penjumlahan terbobot dari rating kinerja pada setiap alternatif dari semua atribut, metode SAW membutuhkan proses normalisasi matrik keputusan (x) ke suatu skala yang dapat diperbandingkan dengan dengan semua rating alternatif yang ada Langkah Penyelesaian SAW:

1. Menentukan alternatif, yaitu $A_{i}$.

2. Menentukan kriteria yang akan dijadikan acuan dalam pengambilan keputusan, yaitu $\mathrm{C} j$.

3. Memberikan nilai rating kecocokan setiap alternatif pada setiap kriteria.

4. Menentukan bobot preferensi atau tingkat kepentingan (W) setiap kriteria.

5. Membuat matrik keputusan $X$ yang dibentuk dari tabel rating kecocokan dari setiap alternatif pada setiap kriteria. Nilai $x$ setiap alternatif (Ai) pada setiap criteria $(\mathrm{Cj})$ yang sudah ditentukan, dimana, $i=1,2, \ldots m$ dan $j=1,2, \ldots . n$.

$$
W=\left[\begin{array}{lllll}
W_{1} & W_{2} & W_{3} & \ldots & W_{j}
\end{array}\right]
$$

6. Melakukan normalisasi matrik keputusan dengan cara menghitung nilai rating kinerja ternomalisasi (rij) dari alternatif Ai pada kriteria $\mathrm{Cj}$.

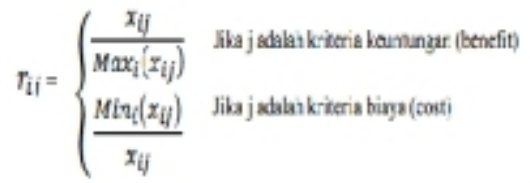

Keterangan :

a. Dikatakan kriteria keuntungan apabila nilai $x \mathrm{ij}$ memberikan keuntungan bagi pengambil keputusan, sebaliknya kriteria biaya apabila $x \mathrm{ij}$ menimbulkan biaya bagi pengambil keputusan.

b. Apabila berupa kriteria keuntungan maka nilai xij dibagi dengan nilai Maxi(xij)dari setiap kolom, sedangkan untuk kriteria biaya, nilai Mini (xij) dari setiap kolom dibagi dengan nilai $x \mathrm{ij}$.

$X=\left[\begin{array}{cccc}x_{11} & x_{12} & \cdots & x_{1 j} \\ & \vdots & & \vdots \\ x_{11} & x_{12} & \cdots & x_{11}\end{array}\right]$

7. Hasil dari nilai rating kinerja ternomalisasi (rij) membentuk matrik ternormalisasi $(\mathrm{R})$

$$
R=\left[\begin{array}{cccc}
r_{11} & r_{12} & \cdots & r_{1 j} \\
& \vdots & & \vdots \\
r_{i 1} & r_{i 2} & \cdots & r_{i j}
\end{array}\right]
$$

8. Hasil akhir nilai preferensi (Vi) diperoleh dari penjumlahan dari perkalian elemen baris matrik ternormalisasi (R) dengan bobot preferensi (W) yang bersesuaian eleman kolom matrik (W).

$$
V_{i}=\sum_{j=1}^{n} w_{j} r_{i j}
$$

\section{HASIL DAN PEMBAHASAN}

1. Menentukan alternatif, yaitu $\mathrm{A}_{\mathrm{i}}$. Tabel. 1 menampilkan nama-nama revisi calon penerima Rastra yang pada akhir proses akan diranking dari yang paling layak sampai yang kurang layak. 
TABEL I KANDIDAT CALON PENERIMA RASTRA

\begin{tabular}{|l|}
\hline \multicolumn{1}{|c|}{ Alternatif $\left(\mathrm{A}_{\mathrm{i}}\right)$} \\
\hline Akron Lapasi \\
\hline Yusuf Yadi \\
\hline Rahman Amuntu \\
\hline Yusuf Muhdin \\
\hline Nurdin Hadi \\
\hline Hariyanti Husain \\
\hline Abd. Wahid Yadi \\
\hline Abdullah Miungo \\
\hline Hamizah Mohune \\
\hline Mansur Ladawo \\
\hline
\end{tabular}

2. Menentukan kriteria yang akan dijadikan acuan dalam pengambilan keputusan, yaitu $\mathrm{Cj}$. Berdasarkan buku panduan Rastra, penerima Rastra yang berdasarkan Data Penerima Manfaat (DPM) dapat direvisi tiap tahunnya melalui musyawarah desa berdasarkan kriteria berikut (Tabel. 2).

TABEL II

KRITERIA PERUBAHAN CALON PENERIMA RASTRA

\begin{tabular}{|l|l|}
\hline & Kriteria $\left(\mathrm{C}_{\mathrm{j}}\right)$ \\
\hline $\mathrm{C} 1$ & Jumlah Tanggungan \\
\hline $\mathrm{C} 2$ & Total Balita dan Anak Usia Sekolah \\
\hline $\mathrm{C} 3$ & kepala keluarga wanita \\
\hline C4 & Kondisi Kelayakan Rumah \\
\hline C5 & Jumlah Penghasilan \\
\hline C6 & Kepemilikan Rumah \\
\hline
\end{tabular}

3. Memberikan nilai setiap alternatif pada setiap kriteria. Untuk memberikan nilai alternatif pada setiap kriteria, maka ditentukan terlebih dahulu bobot setiap kriteria. Bobot 4 merupakan nilai tertinggi dan bobot 1 merupakan nilai terendah. Pemberian nilai bobot merupakan hasil wawancara

Tabel. 3 adalah pembobotan untuk atribut jumlah tanggungan dan total balita dan anak usia sekolah. Jika memiliki 4 anak atau lebih diberikan bobot paling tinggi yaitu 4 .
TABEL III

BOBOT ATRIBUT JUMLAH TANGGUNGAN DAN TOTAL BALITA DAN ANAK USIA SEKOLAH

\begin{tabular}{|l|c|}
\hline \multicolumn{1}{|c|}{ Jumlah Tanggungan } & Bobot \\
\hline 4 anak atau lebih & 4 \\
\hline 3 anak & 3 \\
\hline 2 anak & 2 \\
\hline 1 anak atau tidak punya & 1 \\
\hline
\end{tabular}

Tabel. 4 adalah tabel untuk bobot kepala keluarga, dimana jika kepala keluarganya seorang wanita maka diberikan bobot 4 dan kepala keluarga laki laki diberikan bobot 1 .

TABEL IV BOBOT KEPALA KELUARGA

\begin{tabular}{|l|c|}
\hline \multicolumn{1}{|c|}{ Atribut } & Bobot \\
\hline Kepala Keluarga Wanita & 4 \\
\hline Kepala Keluarga laki - laki & 1 \\
\hline
\end{tabular}

Tabel. 5 adalah bobot untuk kondisi rumah, dimana rumah bambu anyam memiiki bobot tertinggi yaitu 4 dan rumah permanen dari batu memiliki bobot 1

TABEL V

BOBOT UNTUK KONDISI RUMAH

\begin{tabular}{|l|c|}
\hline \multicolumn{1}{|c|}{ Jenis Rumah } & Bobot \\
\hline Bambu anyam & 4 \\
\hline Kayu semi permanen (kayu) & 3 \\
\hline Permanen (batu dan semen) & 1 \\
\hline
\end{tabular}

Tabel. 6 adalah bobot untuk jumlah penghasilan dimana penghasilan dibawah Rp.500.000 berbobot paling tinggi yaitu 4 dan penghasilan diatas Rp.1.500.000 memilikii bobot paling rendah.

TABEL VI

BOBOT UNTUK JUMLAH PENGHASILAN

\begin{tabular}{|l|c|}
\hline \multicolumn{1}{|c|}{ Jumlah Penghasilan } & Bobot \\
\hline$<500.000$ & 4 \\
\hline $500.000 \mathrm{~s} / \mathrm{d} 1.000 .000$ & 3 \\
\hline $1.000 .000 \mathrm{~s} / \mathrm{d} 1.500 .000$ & 2 \\
\hline$>1.500 .000$ & 1 \\
\hline
\end{tabular}

Tabel. 7 Adalah bobot untuk pembobotan untuk jenis pekerjaan yaitu pengguran diberikan bobot 4 dan Buruh diberikan bobot 3 dan pedangan memiliki bobot 2 .

TABEL VII

BOBOT UNTUK JENIS PEKERJAAN

\begin{tabular}{|l|c|}
\hline \multicolumn{1}{|c|}{ Jenis Pekerjaan } & Bobot \\
\hline Pengangguran & 4 \\
\hline Buruh & 3 \\
\hline Pedangang & 2 \\
\hline
\end{tabular}

Tabel. 8 adalah alternatif yang telah diberikan nilai berdasarkan bobot kriteria yang telah ditentukan diatas. 
TABEL VIII

NILAI ALTERNATIF PADA SETIAP KRITERIA

\begin{tabular}{|l|c|c|c|c|c|c|}
\hline Alternatif & C1 & C2 & C3 & C4 & C5 & C6 \\
\hline Akron Lapasi & 4 & 4 & 1 & 4 & 2 & 3 \\
\hline Yusuf Yadi & 3 & 3 & 1 & 4 & 2 & 3 \\
\hline Rahman Amuntu & 2 & 3 & 1 & 3 & 3 & 2 \\
\hline Yusuf Muhdin & 2 & 3 & 1 & 2 & 2 & 3 \\
\hline Nurdin Hadi & 3 & 4 & 1 & 3 & 2 & 4 \\
\hline Hariyanti Husain & 2 & 1 & 4 & 2 & 2 & 2 \\
\hline $\begin{array}{l}\text { Abd. Wahid } \\
\text { Yadi }\end{array}$ & 3 & 2 & 1 & 4 & 1 & 2 \\
\hline $\begin{array}{l}\text { Abdullah } \\
\text { Miungo }\end{array}$ & 3 & 3 & 1 & 4 & 1 & 4 \\
\hline $\begin{array}{l}\text { Hamizah } \\
\text { Mohune }\end{array}$ & 2 & 3 & 4 & 2 & 2 & 1 \\
\hline Mansur Ladawo & 3 & 3 & 1 & 3 & 2 & 3 \\
\hline
\end{tabular}

4. Menentukan bobot preferensi atau tingkat kepentingan (W) setiap kriteria. Bobot kepentingan setiap kriteria diberikan, berdasarkan hasil wawancara dengan aparat desa. Tabel. 9 menampilkan bobot dari setiap kriteria.

TABEL IX

BOBOT PERSENTASE DARI SETIAP KRITERIA

\begin{tabular}{|l|l|c|}
\hline $\begin{array}{c}\text { Simb } \\
\text { ol }\end{array}$ & \multicolumn{1}{|c|}{ Kriteria } & $\begin{array}{c}\text { Bobot } \\
\text { (W) }\end{array}$ \\
\hline C1 & Jumlah Tanggungan & $20 \%$ \\
\hline C2 & $\begin{array}{l}\text { Total Balita dan Anak Usia } \\
\text { Sekolah }\end{array}$ & $15 \%$ \\
\hline C3 & kepala keluarga wanita & $5 \%$ \\
\hline C4 & Kondisi Kelayakan Rumah & $20 \%$ \\
\hline C5 & Jumlah Penghasilan & $30 \%$ \\
\hline C6 & Kepemilikan Rumah & $10 \%$ \\
\hline
\end{tabular}

5. Melakukan normalisasi matrik alternatif terhadap kriteria. Normalisasi didapatkan dengan menggunakan rumus 2. Tabel. 10 merupakan hasil matriks ternormalisasi.

TABEL X

MATRIKS ALTERNATIF TERNORMALISASI

\begin{tabular}{|l|c|c|c|c|c|c|}
\hline r11 & 1 & 1 & 4 & 1 & 5 & 333 \\
\hline r12 & $\begin{array}{c}1,3333 \\
33333\end{array}$ & $\begin{array}{c}1,333 \\
333\end{array}$ & 4 & 1 & 5 & 333 \\
\hline r13 & 2 & $\begin{array}{c}1,333 \\
333\end{array}$ & 4 & $\begin{array}{c}1,333 \\
333\end{array}$ & 1 & 2 \\
\hline \multirow{2}{*}{ r14 } & 2 & 1,333 & & & 1, & 1,333 \\
\hline \multirow{2}{*}{ r15 } & 1,3333 & 333 & 4 & 2 & 5 & 333 \\
\hline \multirow{2}{*}{ r16 } & 33333 & 1 & 4 & 333 & 5 & 1 \\
\hline \multirow{2}{*}{ r17 } & 1,3333 & & & & 1,333 & \\
\hline
\end{tabular}

\begin{tabular}{|l|c|c|c|c|c|c|}
\hline $\mathrm{r} 18$ & 1,3333 & 1,333 & & & & \\
& 33333 & 333 & 4 & 1 & 3 & 1 \\
\hline \multirow{2}{*}{$\mathrm{r} 19$} & & 1,333 & & & 1, & \\
& 2 & 333 & 1 & 2 & 5 & 4 \\
\hline \multirow{2}{*}{$\mathrm{r} 110$} & 1,3333 & 1,333 & & 1,333 & 1, & 1,333 \\
& 33333 & 333 & 4 & 333 & 5 & 333 \\
\hline
\end{tabular}

6. Matriks keputusan diperoleh dari persamaan 5. Tabel .11 merupakan matriks keputusan yang belum terurut.

TABEL XI

MATRIKS KEPUTUSAN BELUM TERURUT
\begin{tabular}{|l|l|}
\hline $\mathrm{v} 1$ & 1,48 \\
\hline $\mathrm{v} 2$ & 1,60 \\
\hline $\mathrm{v} 3$ & 2,17 \\
\hline $\mathrm{v} 4$ & 1,93 \\
\hline $\mathrm{v} 5$ & 1,58 \\
\hline $\mathrm{v} 6$ & 2,25 \\
\hline $\mathrm{v} 7$ & 1,47 \\
\hline $\mathrm{v} 8$ & 1,27 \\
\hline $\mathrm{v} 9$ & 2,05 \\
\hline $\mathrm{v} 10$ & 1,67 \\
\hline
\end{tabular}

7. Hasil Ranking matriks keputusan ditampilkan pada Tabel. 12. Pada tabel ini dapat dilihat bahwa alternatif A6 memiliki nilai tertinggi, sehingga merupakan alternatif terlayak untuk menjadi calon penerima Rastra. Alternatif A8 merupakan alternatif yang kurang layak untuk menjadi calon penerima Rastra. Tabel. 12

TABEL XII

MATRIKS KEPUTUSAN TERUR
\begin{tabular}{|l|l|}
\hline A6 & 2,25 \\
\hline A3 & 2,17 \\
\hline A9 & 2,05 \\
\hline A4 & 1,93 \\
\hline A10 & 1,67 \\
\hline A2 & 1,60 \\
\hline A5 & 1,58 \\
\hline A1 & 1,48 \\
\hline A7 & 1,47 \\
\hline A8 & 1,27 \\
\hline
\end{tabular}

\section{KESIMPULAN}

Metode SAW dapat digunakan untuk perubahan calon penerima Rastra, karena dapat memberikan ranking untuk calon penerima Rastra mulai dari yang paling layak sampai yang kurang layak. 


\section{REFERENS}

[1] Andrianto, R. Sistem Pendukung Keputusan Seleksi Penerima Beras Untuk Keluarga Miskin (Raskin) Pada Desa Golantepus Dengan Metode Simple Additive Weighting (SAW). Laporan Skripsi Universitas Muria Kudus. 2013.

[2] Sofyan F., Nurfarida E., Yustika, W.E. 2016. Sistem Pendukung Keputusan Penerimaan Raskin Desa Mabung Kabupaten Nganjuk Menerapkan Metode Simple Additive Weighting (SAW). Jurnal Informatika dan Mutimedia, Vol. 08, No.02.

[3] Angrawati D, Yamin M dan Ransi N. Sistem Pendukung Keputusan Menentukan Jumlah Beras Miskin Menggunakan Metode Simple Additive Weight (SAW). SemantTik, Vol.2, No.1, Jan -Jun 2016, pp.39-46.

[4] Ekawati, A. 2012. Sistem Pendukung Keputusan Pembagian Raskin dengan Metode Simple Additive Weighting (SAW). Laporan Skripsi Program Studi Teknik Informatika, Universitas Dian Nuswantoro. 